\title{
Notes and Announcements
}

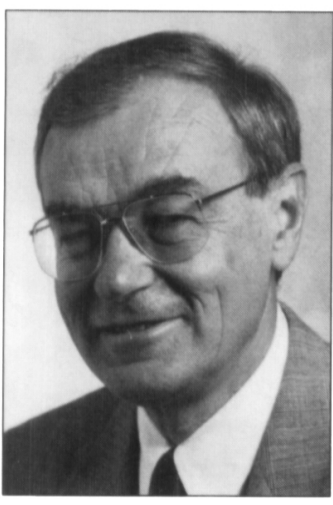

\section{Dr. Vladimir Hackinski elected Vice President of the World Federation of Neurology}

Vladimir Hachinski, Richard \& Beryl Ivey Professor and Chair, Department of Clinical Neurological Sciences, University of Western Ontario, was elected Vice President (North America) of the World Federation of Neurology (WFN) at the XVI World Congress of Neurology held in Buenos Aires on September 14-19, 1997

Dr. Hachinski served as Chair of the WFN Steering Committee, which introduced a number of changes, making the WFN more democratic and participatory. As Vice President, Dr. Hackinski intends to continue to have an activist role, particularly in regard to neurology in the developing world.
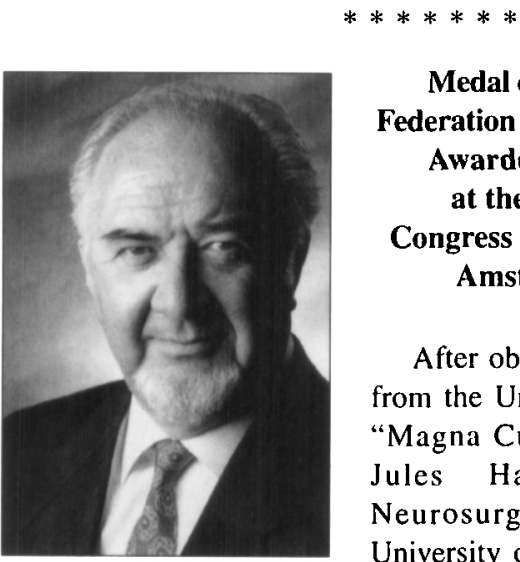

Medal of Honor of the World Federation of Neurosurgical Societies Awarded to Dr. Jules Hardy at the 11th International Congress of Neurological Surgery Amsterdam - July 1997

After obtaining his medical degree from the University of Montreal with "Magna Cum Laude" in 1956, Dr. Jules Hardy completed his Neurosurgical Residency at the University of Montreal and spent one year at Hopital Foch in Paris where his contacts with Professor Gerard Guiot would have a determining influence on his future career. He then obtained his certification in Neurosurgery as a Fellow of the Royal College of Surgeons of Canada in 1962 and was appointed staff Neurosurgeon at Notre Dame Hospital and University of Montreal where he first performed transsphenoidal approaches for pituitary adenomas. Soon after he introduced a substantial innovation, namely the combined use of intraoperative magnification with a surgical microscope and intraoperative televised radio-fluoroscopy which were to be universally used throughout the world. Later on, he further refined original micro instruments adapted to pituitary microsurgery which soon became known as Hardy's Instrumentation.

With these refinements he was able to demonstrate the possibility to spare the normal remaining pituitary gland during removal of pituitary adenomas, thus reducing significantly the incidence of long-term post-operative pituitary insufficiency and even allowing restoration of normal pituitary functions. His major contribution to the field of neuro-endocrinology was the recognition and demonstration of pituitary microadenomas and their selective removal in the treatment of hyperpituitarism allowing innumerable women with micro prolactinomas to become pregnant and also improving remarkably the treatment results of acromegaly. His original method of microadenomectomy finally gained a consensus for the treatment of Cushing's disease in 1988. He also developed an original classification of pituitary adenomas with Dr. Jean Vezina, Neuroradiologist, using a grading system of the sella turcica modifications and suprasellar extensions allowing standardization of surgical stategy and improving prediction of results, later adapted to CT and MRI. He also first demonstrated the topographical localization of microadenomas in the human pituitary.

In 1976, Jules Hardy became professor of Neurosurgery at the University of Montreal and was Chairman of the Division of Neurosurgery from 1979 until 1985. He was also appointed consultant neurosurgeon at the Montreal General Hospital and adjunct professor of Neurosurgery at McGill University. In 1982 he was elected President of the Canadian Congress of Neurological Sciences and has received numerous prestigious international awards, amongst which the Medal of Honor of the World Federation of Neurosurgical Society in July 1997, the highest award attributed to neurosurgeons by their peers. He receive an Honorary Doctorate from the University of Guadalajara, Mexico in 1979, was appointed Sir Arthur Sims Commonwealth Travelling Professor in 1983. He was made Officer of the Order of Canada in 1987 and he received the Commemorative Medal of the 150th Anniversary of the Confederation of Canada in 1992.

Dr. Hardy's contributions to the field of pituitary microsurgery and neuroendocrinology in general will have a lasting impact on the management of pituitary tumors. During the 35 years of his neurosurgical practice, Dr. Hardy has been a prolific writer and has authored over 150 articles and monographs including an atlas of Transsphenoidal Microsurgery in Pituitary Tumors. He has given lectures on all continents and performed surgery in many countries. He has conducted himself more than 2,700 transsphenoidal pituitary operations which will remain one of the largest series performed by one single surgeon. His career has been exemplary both from the professional and academic standpoints and his important contributions as a single individual have given Canadian medicine and neurosurgery a remarkable radiance.

Gérard Mohr Montreal, Quebec

$$
* * * * * * *
$$

\section{Life Sciences Achievement Award recipients honoured}

The Ottawa Life Sciences Council honoured outstanding achievement in the Life Sciences Sector at its 4th Annual Awards Gala on October 28, 1997 in Ottawa. Among the recipients of the 1997 awards were:

\section{Dr. Leo Renaud - Basic Research Award}

Dr. Leo Renaud, of the Loeb Research Institute, began his career in science in Ottawa - first receiving his BA degree and then his MD degree from the University of Ottawa. After an MRC Fellowship, Dr. Renaud completed a PhD and was appointed Assistant Professor at McGill in 1973. In 1990, he moved to Ottawa to become the Director of the Division of Neurology at the Civic Hospital and Associate Director of the Loeb Research Institute. 
Dr. Renaud's research has consistently dealt with the fundamental mechanisms governing neuronal excitability, and mechanisms of neurotransmitter action. He is a pioneer in the development and application of electrophysiological techniques to the study of the neurohyophyseal system. The techniques developed in his lab have enabled Dr. Renaud to make fundamental contributions to an understanding of regulation of vasopression - a hormone vitally important for the regulation of blood pressure and water balance.

\section{Dr. David Grimes - Career Achievement Award}

Dr. David Grimes, Founder and CEO, Loeb Research Institute, primary area of research has been in the field of Parkinson's disease where he has made significant contributions, particularly in the clinical research field. His contributions have been recognized internationally and he has advanced the development of many new therapies through controlled clinical trials.

Perhaps his most important contribution to medical research in Canada is the founding of the Loeb Research Institute in 1987. The Institute supports (directly and indirectly through external funding) over 200 positions including 35 scientists, 100 graduate and postgraduate students and over 100 technicians and research assistants. The Institute receives over $\$ 10$ million dollars in funding from peer review agencies and industry. He has been instrumental in bringing the best bright minds to Ottawa and ensuring that they develop working partnerships with industry, clinicians, and researchers, both nationally and internationally.

\section{Inauguration of the Alan R. Hudson Teaching Awards of the Division of Neurosurgery at the University of Toronto}

The Division of Neurosurgery at the University of Toronto has created the Alan R. Hudson Faculty Teaching Award and the Alan R. Hudson Resident Teaching Award to be given annually in recognition of Professor Alan R. Hudson's major contributions to neurosurgical teaching during his tenure as Chair of the Division of Neurosurgery at the University of Toronto.

The first Awards were presented recently at the 1997 E. Harry Botterell Professorship in Neurosurgery held at The Toronto Hospital, Western Division. Dr. Fred Gentili was the winner of the Faculty Teaching Award for his excellent contribution to undergraduate and postgraduate teaching, and Dr. Nalin Gupta was the winner of the Resident Teaching Award for his excellent contributions to the teaching of medical students, fellow residents and nurses.

\section{Electromyography Examinations}

The following candidates successfully completed their 1997 examinations held in Vancouver, British Columbia on September 27, 1997:
N. Ashworth
M. Jan
C. Boyle
M.L. Myles
C. Todd
M. Stitz
M. Di Persio
J. Wee
J. Flannery
C. White 